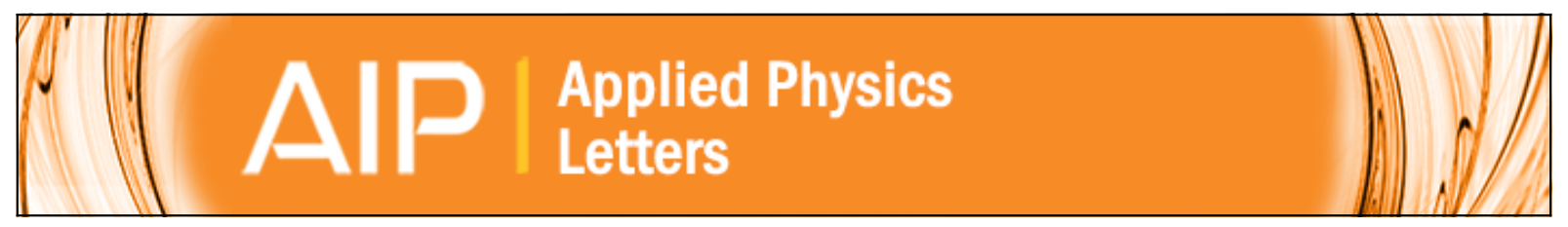

\title{
Oriented growth of SrBi2Ta2O9 ferroelectric thin films
}

Seshu B. Desu, Dilip P. Vijay, X. Zhang, and BaoPing He

Citation: Applied Physics Letters 69, 1719 (1996); doi: 10.1063/1.118008

View online: http://dx.doi.org/10.1063/1.118008

View Table of Contents: http://scitation.aip.org/content/aip/journal/apl/69/12?ver=pdfcov

Published by the AIP Publishing

\section{Articles you may be interested in}

$18 \mathrm{O}$ isotopic tracer studies of the laser ablation of Bi2Sr2Ca1Cu2O8

J. Appl. Phys. 80, 1787 (1996); 10.1063/1.362989

Influence of laser energy density on the plasma expansion dynamics and film stoichiometry during laser ablation of $\mathrm{BiSrCaCuO}$

J. Appl. Phys. 79, 8042 (1996); 10.1063/1.362357

Structural and optical properties of laser deposited ferroelectric (Sr0.2Ba0.8)TiO3 thin films

J. Appl. Phys. 79, 7965 (1996); 10.1063/1.362346

Electrical properties of $\mathrm{SrBi2Ta2O9}$ thin films and their temperature dependence for ferroelectric nonvolatile memory applications

Appl. Phys. Lett. 68, 2300 (1996); 10.1063/1.116170

Effects of deposition rate on $\mathrm{Bi} 2 \mathrm{Sr} 2 \mathrm{CaCu} 2 \mathrm{O} 8+x$ and $\mathrm{Bi} 2 \mathrm{Sr} 1.6 \mathrm{La} 0.4 \mathrm{CuO} 6+\mathrm{x}$ epitaxial thinfilm growth by pulsed laser ablation

AIP Conf. Proc. 288, 237 (1993); 10.1063/1.44914

\section{AlP Re-register for Table of Content Alerts}

\section{Create a profile.

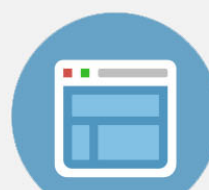 \\ Sign up today!}




\title{
Oriented growth of $\mathrm{SrBi}_{2} \mathrm{Ta}_{2} \mathrm{O}_{9}$ ferroelectric thin films
}

\author{
Seshu B. Desu, Dilip P. Vijay, X. Zhang, and BaoPing He \\ Department of Materials Science and Engineering, Virginia Polytechnic Institute and State University, \\ Blacksburg, Virginia 24061
}

(Received 10 November 1995; accepted for publication 10 May 1996)

\begin{abstract}
We report on the ferroelectric properties of $c$-axis oriented ferroelectric $\mathrm{SrBi}_{2} \mathrm{Ta}_{2} \mathrm{O}_{9}$ thin films. $\mathrm{Pt} / \mathrm{SrBi}_{2} \mathrm{Ta}_{2} \mathrm{O}_{9} / \mathrm{Pt}$ capacitors were grown on single crystal $\mathrm{MgO}$ (and/or $\mathrm{SrTiO}_{3}$ ) substrates using pulsed laser ablation. These substrates provide the necessary template for (100) texture in platinum due to their close lattice matching. This in turn facilitates the $c$-axis orientation in the ferroelectric films. The degree of orientation in the layered structure ferroelectric film was systematically varied from highly $c$-axis oriented to random polycrystalline by varying the growth conditions of the bottom metal electrode. The polarization and coercive field values were found to decrease with an increasing degree of $c$-axis orientation; while the randomly oriented films exhibited a remnant polarization of $5 \mu \mathrm{C} / \mathrm{cm}^{2}$, a coercive field of $70 \mathrm{kV} / \mathrm{cm}$, and a dielectric constant of 320 , the $c$-axis oriented films exhibited very low polarization $\left(\sim 1 \mu \mathrm{C} / \mathrm{cm}^{2}\right)$, coercivity $(22 \mathrm{kV} / \mathrm{cm})$, and dielectric constant ( 200) values. (C) 1996 American Institute of Physics. [S0003-6951(96)02728-3]
\end{abstract}

Recently, new ferroelectric oxides belonging to the family of layered perovskites were identified as promising candidates for degradation-free nonvolatile memory applications; $\mathrm{SrBi}_{2} \mathrm{Ta}_{2} \mathrm{O}_{9}$ (SBT) thin films were found to exhibit no fatigue up to $10^{12}$ cycles, excellent retention characteristics and very low leakage currents on Pt electrodes. ${ }^{1-4}$ The promise that these materials hold for memory applications can be realized by the fact there are ongoing efforts to fabricate fully functional $256-\mathrm{kb}$ and higher density RAMs. ${ }^{5}$ But the application of these materials to memories on a large scale is not without problems. In particular, the processing of these layered perovskite structure oxides is not as straightforward as in the case of perovskite ferroelectrics such as PZT and is in the incipient stages of understanding. Higher processing temperatures $\left(>700{ }^{\circ} \mathrm{C}\right)$ are required to obtain good ferroelectric properties in these materials which is a major limitation in terms of VLSI processing. ${ }^{1-4}$ The values of the remnant polarization and coercive field commonly exhibited by these materials are on the lower limit of that required for nonvolatile memory applications. Furthermore, the ferroelectric properties (e.g., remnant polarization, coercive field, dielectric constant, etc.) are highly sensitive to the processing conditions and the processing method.

Structurally, the bismuth layered perovskite ferroelectrics are highly anisotropic in nature and therefore the ferroelectric properties (spontaneous polarization, coercive field, dielectric constant, etc.) are strongly dependent on the orientation of the films with respect to the underlying substrate materials. The ferroelectric properties along the major axes are fairly simple to characterize in bulk compound ferroelectric materials since crystal sections can be cut in such a way as to facilitate the application of high fields along different crystallographic directions. However, the properties in bulk compounds can never be truly replicated in the corresponding thin films. For the case of $\mathrm{SrBi}_{2} \mathrm{Ta}_{2} \mathrm{O}_{9}$ thin films, the ferroelectric properties along the different crystallographic orientations have not been characterized so far. This is primarily because of the difficulty in orienting these thin films along the different crystallographic directions relative to the underlying substrate materials. For memory applications, as mentioned before, the SBT films are usually grown on top of the Pt bottom electrodes. The bottom Pt layer is grown on oxidized single-crystal silicon substrates with a Ti interlayer for adhesion purposes. However, in this structure, the $\mathrm{Pt}$ films are almost always oriented with the (111) planes parallel to the film surface at any given deposition temperature. This poses a severe limitation on controlling the orientation of the ferroelectric film on top of the Pt layer as exemplified by the case of SBT films grown on Pt electrodes by the metalorganic decomposition method wherein, the films are almost always polycrystalline at the final processing temperatures. The occurrence of a favorable orientation during film growth is critically controlled by the lattice parameter ratio of the film and substrate material. In this work, we have devised a novel device structure for growth of $\mathrm{Pt} / \mathrm{SBT} / \mathrm{Pt}$ capacitors that provides us with the flexibility of varying the orientation in the ferroelectric film with minor changes in the processing conditions. This not only has important technological implications in the fact that it permits the tailoring of the ferroelectric properties of the capacitor structure but now also provides opportunities to understand, at a fundamental level, the ferroelectric behavior of these materials.

In the proposed device structure, the SBT film and the underlying Pt electrode is grown on top of a highly oriented or epitaxial $\mathrm{MgO}(100)$ (and/or $\mathrm{SrTiO}_{3}$ ) layer. SBT belongs to the Aurivillus family of mixed bismuth oxides with the general formula $\left(\mathrm{Bi}_{2} \mathrm{O}_{2}\right)^{2+}\left(\mathrm{A}_{m-1} \mathrm{~B}_{m} \mathrm{O}_{3 m+1}\right)^{2-}$, where $\mathrm{A}$ and $\mathrm{B}$ are metal ions and $m$ is a numeral: $\mathrm{A}=\mathrm{Sr}^{3+}, \mathrm{B}=\mathrm{Ta}^{4+}$, and $m=2$ for $\mathrm{SrBi}_{2} \mathrm{Ta}_{2} \mathrm{O}_{9} .{ }^{6-8}$ The unit cell consists of stacking two perovskite-like units of nominal composition $\mathrm{ABO}_{3}$ between $\mathrm{Bi}_{2} \mathrm{O}_{3}$ layers, with a pseudotetragonal structure wherein $a=0.38 \mathrm{~nm}$ and $c=2.51 \mathrm{~nm}$. fcc Pt has the same lattice constant as that reported for pseudotetragonal SBT films $(a=0.389 \mathrm{~nm})$. This indicates that for favorable growth of SBT films along the $c$ axis, the underlying Pt films need to be grown with a (100) preferred orientation. $\mathrm{MgO}(100)$ or $\mathrm{SrTiO}_{3}(100)$ can be chosen as template layers in this device structure because of their close lattice match to Pt. $\mathrm{MgO}$ is a highly insulating crystalline solid with the $\mathrm{NaCl}$ structure and has only a $7.4 \%$ mismatch in lattice constant with plati- 


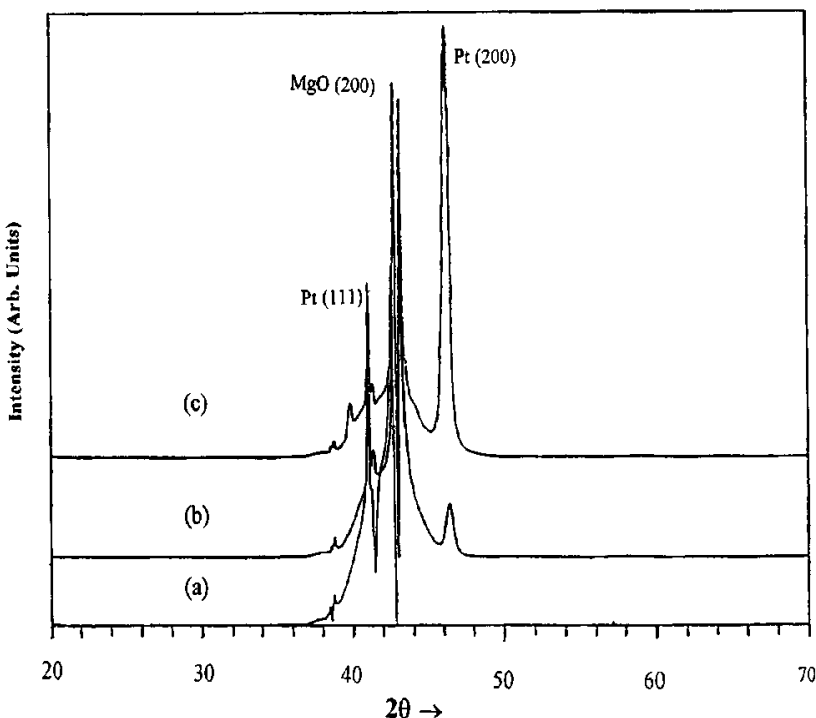

FIG. 1. X-ray diffraction patterns of Pt films sputter deposited on singlecrystal $\mathrm{MgO}(100)$ substrates as a function of deposition temperature; (a) room-temperature deposition, (b) $600{ }^{\circ} \mathrm{C}$ deposition, and (c) $700{ }^{\circ} \mathrm{C}$ deposition.

num while $\mathrm{SrTiO}_{3}$ has an even lower lattice misfit of only $0.4 \%$. Therefore, it is possible to grow highly oriented $\mathrm{Pt}(100)$ on $\mathrm{MgO}(100)$ or $\mathrm{SrTiO}_{3}$ albeit at a high deposition temperature $\left(600-700{ }^{\circ} \mathrm{C}\right)$. The preferred growth of substrates such as $\mathrm{MgO}(100)$ on $\mathrm{Si}(100)$ has been reported previously for both epitaxial and nonepitaxial depositions. ${ }^{9}$ Thus, the complete device structure can be grown on the preferred single-crystal $\mathrm{Si}(100)$ substrates for VLSI applications.

In this study, the Pt films were grown on top of singlecrystal $\mathrm{MgO}(100)$ substrates by the sputtering process. The films were deposited at three different substrate temperatures-room temperature, 600 and $700{ }^{\circ} \mathrm{C}$ under the conditions of: argon gas pressure $=5 \mathrm{mTorr}$ and $\mathrm{rf}$ power $=10$ $\mathrm{W}$. The deposition rate at high temperatures was typically in the range of: $0.1-0.3 \mathrm{~nm} / \mathrm{s}$. After deposition, the films were cooled at a rate of $20^{\circ} \mathrm{C} / \mathrm{min}$ to room temperature in the sputtering chamber itself. $\mathrm{SrBi}_{2} \mathrm{Ta}_{2} \mathrm{O}_{9}$ films were deposited by the technique of pulsed laser ablation ( $248 \mathrm{~nm}, \mathrm{KrF}$ laser) on these platinum coated $\mathrm{MgO}$ substrates at a deposition temperature of $700{ }^{\circ} \mathrm{C}$, frequency of $10 \mathrm{~Hz}$, beam energy of $700 \mathrm{~mJ}$, and $\mathrm{O}_{2}$ partial pressure of $200 \mathrm{mTorr}$. The details of the deposition system are described elsewhere. ${ }^{10}$ The growth rate of the films under these conditions was typically 0.2 $\mathrm{nm} / \mathrm{s}$ and the thickness of all the films were $200 \mathrm{~nm}$ as verified by spectroscopic ellipsometry. The films were characterized for structure by the X-ray diffraction (XRD) technique using $\mathrm{Cu} K \alpha$ radiation. In the case of SBT films, the diffraction patterns were recorded only between $2 \theta$ values of $10^{\circ}$ and $35^{\circ}$ to avoid any scaling problems due to strong diffraction peaks from the underlying Pt films. Countertop electrodes of Pt (contact area $=0.00021 \mathrm{~cm}^{2}$ ) were sputter deposited at room temperature on the top surface for electrical characterization of the films in the metal-ferroelectric-metal structure. The ferroelectric properties were measured using a computer controlled Sawyer-Tower circuit at an applied voltage of $5 \mathrm{~V}$. The dielectric properties $(200-1000 \mathrm{kHz})$

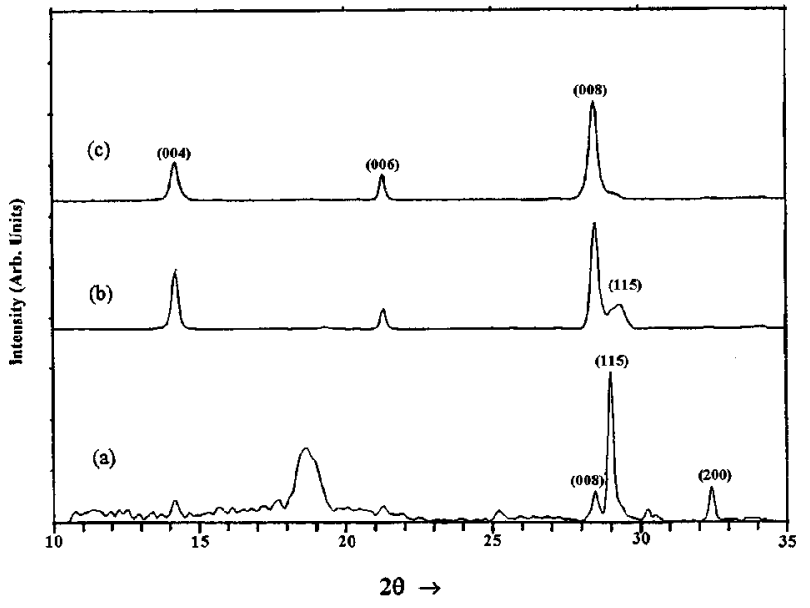

FIG. 2. X-ray diffraction patterns of $\mathrm{SrBi}_{2} \mathrm{Ta}_{2} \mathrm{O}_{9}$ thin films deposited on (a) $\mathrm{MgO} / \mathrm{Pt}(\mathrm{RT}),(\mathrm{b}) \mathrm{MgO} / \mathrm{Pt}\left(600^{\circ} \mathrm{C}\right)$, and $(\mathrm{c}) \mathrm{MgO} / \mathrm{Pt}\left(700^{\circ} \mathrm{C}\right)$ substrates at a substrate temperature of $700{ }^{\circ} \mathrm{C}$.

were measured at zero bias using an HP 4192 impedance analyzer.

Figure 1 shows the XRD pattern of the Pt films on $\mathrm{MgO}$ (100) substrates as a function of deposition temperature. With increasing deposition temperature, additional reflections were also gathered from the (200) diffraction planes until at a deposition temperature of $700{ }^{\circ} \mathrm{C}$, the Pt films were almost completely oriented with the (100) planes parallel to the substrate surface. Furthermore, rocking curve scans around the $2 \theta$ peak position of the (200) planes (on the films deposited at $700{ }^{\circ} \mathrm{C}$ ) showed a full width at half-maximum value of only $1.4^{\circ}$ indicating a very strong (100) preferred orientation.

Figure 2 shows the XRD pattern of the SBT films deposited on the various $\mathrm{MgO} / \mathrm{Pt}$ substrates. The indexing of the patterns was done by assuming an orthorhombic cell $\left(45^{\circ}\right.$ rotated tetragonal cell) with $a^{\prime}=0.551 \mathrm{~nm}, b^{\prime} / a^{\prime} \sim 1.000$ and $c^{\prime}=2.51 \mathrm{~nm}$. As expected, the room-temperature deposited films showed a strong (111) texture with no reflections from the (200) planes. SBT films deposited on the (111) textured Pt films are randomly polycrystalline under these deposition conditions with predominant diffraction occurring from the (115) planes; also observable are reflections from the $(00 /)$ and (200) planes. However, the films deposited on $\mathrm{MgO}(100) / \mathrm{Pt}(100)$ substrates show a strong $(00 \ell)$ texture as indicated by reflections from only the (004), (006), and (008) planes. For the intermediate case of the films deposited on substrates containing both (100) and (111) oriented Pt films, the predominant orientation in the ferroelectric was still $(00 /)$; however, diffraction peaks of significant intensity were also observed from the (115) planes. In effect, these results indicate that simply by increasing the (100) texture in the underlying Pt bottom electrode, the degree of $c$-axis orientation in the ferroelectric can be increased for the same processing conditions.

Pole figure measurements were made to determine the degree of orientation of the SBT film and the relative orientations of the ferroelectric film and underlying Pt electrode. These measurements were conducted over the tilt range of $\chi=0^{\circ}-80^{\circ}$ in steps of $\Delta \chi=5^{\circ}$ and azimuth angle steps of $\Delta \phi=5^{\circ}$. The pole figures for the three samples are presented 


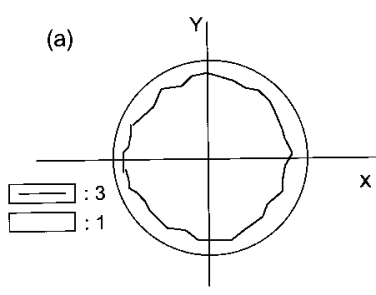

(d)
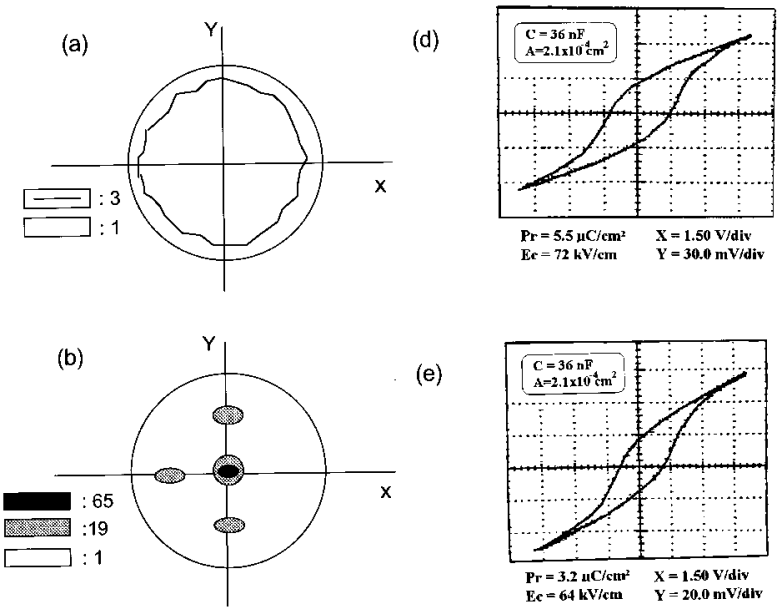

(e)
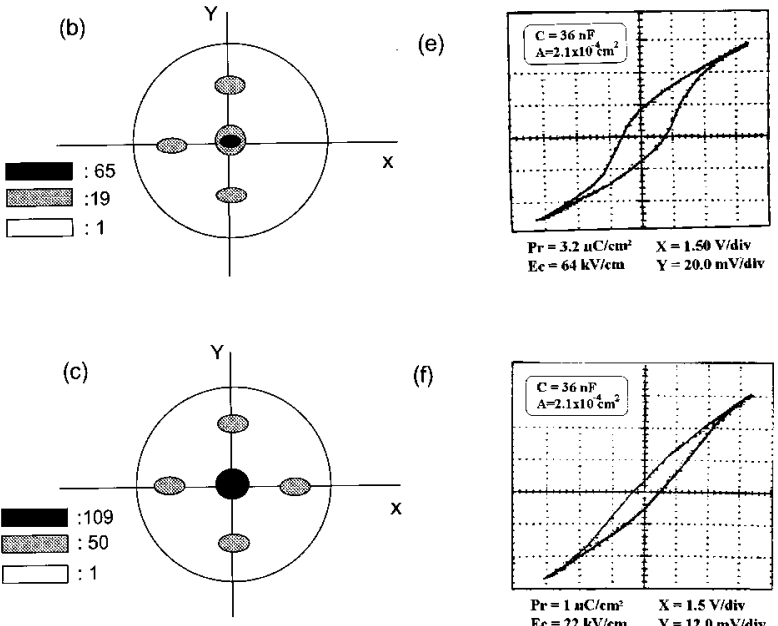

(f)

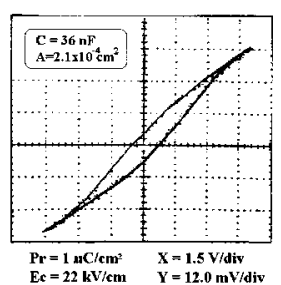

FIG. 3. Pole figure of $\mathrm{SrBi}_{2} \mathrm{Ta}_{2} \mathrm{O}_{9}$ thin films deposited on (a) $\mathrm{MgO} / \mathrm{Pt}$ (RT), (b) $\mathrm{MgO} / \mathrm{Pt}\left(600^{\circ} \mathrm{C}\right)$, and (c) $\mathrm{MgO} / \mathrm{Pt}\left(700^{\circ} \mathrm{C}\right)$ substrates at a substrate temperature of $700{ }^{\circ} \mathrm{C}$. The corresponding hysteresis characteristics of $\mathrm{MgO} / \mathrm{Pt} / \mathrm{SrBi}_{2} \mathrm{Ta}_{2} \mathrm{O}_{9} / \mathrm{Pt}$ capacitors as a function of degree of $c$-axis orientation; (d) $\mathrm{MgO} / \mathrm{Pt}$ (RT)/SBT, (e) $\mathrm{MgO} / \mathrm{Pt}\left(600^{\circ} \mathrm{C}\right) / \mathrm{SBT}$, and (f) $\mathrm{MgO} / \mathrm{Pt}$ $\left(700{ }^{\circ} \mathrm{C}\right) / \mathrm{SBT}$. Ch1 and $\mathrm{Ch} 2$ denote the $x$ - and $y$-axis divisions, respectively.

in Figs. 3(a)-3(c). For the randomly polycrystalline sample [Fig. 3(a)], the pole figure shows no texture as indicated by the pole density value of one, in large range of tilt angle up to $70^{\circ}$. For SBT films deposited on $\mathrm{MgO}(100) / \mathrm{Pt}(100)$ substrates, the pole figures indicate a strong texture. In both these samples, the diffraction intensity from the (008) planes is concentrated in the vicinity of $\chi=0$. For the case of $\mathrm{MgO} /$ $\mathrm{Pt}\left(600{ }^{\circ} \mathrm{C}\right) / \mathrm{SBT}$ films, the $(115)$ intensity is localized within several spots in the tilt angle of $54^{\circ}$ and form a circle around the (008) spot indicating that all the crystals are not aligned in the same orientation in three dimensions. In contrast, the measurements on SBT films deposited on $\mathrm{MgO} / \mathrm{Pt}\left(700^{\circ} \mathrm{C}\right)$ substrates show only four (115) satellite spots making an angle of $\chi=54^{\circ}$ from the sample normal in addition to the (008) intensity concentrated at the center. Since the (115) planes have a fourfold symmetry above the $c$ axis, this pole figure shows that all the crystals are aligned in three dimensions. Furthermore, higher pole density values were obtained from the latter films [Fig. 3(c)] indicating a greater degree of texture.

The electrical properties of the respective films were measured using a simple Sawyer-Tower circuit. ${ }^{10}$ Circular Pt counterelectrodes $\left(2 \times 10^{-4} \mathrm{~cm}^{2}\right.$ in area) were deposited onto the samples through a shadow mask by sputtering. Figures 3(d)-3(f) show the hysteresis plots as a function of degree of $c$-axis orientation in the ferroelectric films. These measurements were conducted at a frequency of $800 \mathrm{~Hz}$ and at an applied voltage of $5 \mathrm{~V}$. Clearly, the polarization and coercive field values decrease systematically with increasing degree of $c$-axis orientation. More importantly, the $c$-axis

oriented films show extremely low polarization values $\left(P_{r}\right.$ $\sim 1 \mu \mathrm{C} / \mathrm{cm}^{2}$ ) and coercive field $(22 \mathrm{kV} / \mathrm{cm})$ values. These results suggest that the $\mathrm{Bi}_{2} \mathrm{O}_{2}$ layers intervening the perovskite-like units along the $c$-axis may not be participating in the cooperative phenomenon responsible for ferroelectricity in these materials. The polarization vector, most likely, lies close to the $a-b$ plane wherein all the perovskitelike layers are continuous. The random polycrystalline films exhibited the highest value of remnant polarization $\left(\sim 5 \mu \mathrm{C} / \mathrm{cm}^{2}\right)$; however, they also showed the highest coercivity $(72 \mathrm{kV} / \mathrm{cm})$. For nonvolatile memory applications, it is preferable to use a ferroelectric material that exhibits high remnant polarization $\left(2 P_{r}>10 \mu \mathrm{C} / \mathrm{cm}^{2}\right)$ along with low coercivity $(<50 \mathrm{kV} / \mathrm{cm})$, but none of the ferroelectric films reported in this study satisfy this criterion. Nonetheless, it is known from previous studies that polycrystalline solid solutions of $\mathrm{SrBi}_{2} \mathrm{Nb}_{2} \mathrm{O}_{9}-\mathrm{SrBi}_{2} \mathrm{Ta}_{2} \mathrm{O}_{9}$ with a composition close to $40 / 60$ exhibits higher polarization values. ${ }^{3}$ Therefore, similar device structures can be fabricated with this material as the ferroelectric layer. The dielectric constant was found to decrease with increasing degree of $c$-axis orientation. For the $c$-axis oriented films, a dielectric constant value of 200 was obtained at room temperature in the frequency range measured (200-1200 kHz).

In summary, the ferroelectric properties of $\mathrm{SrBi}_{2} \mathrm{Ta}_{2} \mathrm{O}_{9}$ ferroelectric thin-film capacitors have been characterized as a function of crystallographic orientation using a novel device structure; the remnant polarization, coercivity, and dielectric constant were found to decrease with increasing degree of $c$-axis orientation. It has been shown that the structural flexibility of these materials can now be used for a wide variety of nonvolatile memory applications ranging from high voltage $(5 \mathrm{~V})$ DRO NvRAMs to low voltage memory applications (single transistor-single capacitor) and nondestructive readout MSFT applications (single transistor). It has also been shown that highly $c$-axis oriented or epitaxial layered structure SBT films exhibit very small polarization, coercivity, and dielectric constant values and are thereby attractive candidates for NDRO MSFT applications.

The authors would like to thank Sharp Corporation, Japan, CERAM-VA and CIT-VA for funding this project. The authors would also like to thank Masaya Nagata, C. L. Thio, Justin Gaynor, and Dr. H. D. Bhatt for their invaluable assistance.

${ }^{1}$ C. A-Paz de Araujo, J. D. Cuchlaro, L. D. McMillan, M. C. Scott, and J. F. Scott, Nature 374, 627 (1995).

${ }^{2}$ K. Ammanuma, T. Hase, and Y. Miyasaki, Appl. Phys. Lett. 66, 221 (1995).

${ }^{3}$ S. B. Desu and D. P. Vijay, Mater. Sci. Eng. B 32, 75 (1995).

${ }^{4}$ S. B. Desu and T. K. Li, Mater. Sci. Eng. B (in press).

${ }^{5}$ C. A-Paz de Araujo, J. D. Cuchlaro, L. D. McMillan, and M. C. Scott, International Pat. Pub. No. WO93/12542 (24 June 1993).

${ }^{6}$ B. Aurivillus, Arkiv Kemi 1, 463 (1949).

${ }^{7}$ G. A. Smolenski, V. A. Isupov, and A. I. Agranovskaya, Fiz. Tverdogo Tela 3, 895 (1961).

${ }^{8}$ E. C. SubbaRao, J. Chem. Phys. 34, 695 (1961).

${ }^{9}$ D. K. Fork, F. A. Ponce, J. C. Tramontana, and T. H. Geballe, Appl. Phys. Lett. 58, 2294 (1991).

${ }^{10}$ C. B. Sawyer and C. H. Tower, Phys. Rev. 35, 239 (1960). 